J Am Chem Soc. 2016 June 22; 138(24): 7796-7800. doi:10.1021/jacs.6b04660.

\title{
Kinetic Resolution of Benzylamines via Palladium(II)-Catalyzed C-H Cross-Coupling
}

\author{
Kai-Jiong Xiao, Ling Chu, Gang Chen, and Jin-Quan Yu* \\ Department of Chemistry, The Scripps Research Institute, 10550 N. Torrey Pines Road, La Jolla, \\ CA 92037
}

\begin{abstract}
A Pd(II)-catalyzed enantioselective $\mathrm{C}-\mathrm{H}$ cross-coupling of benzylamines via kinetic resolution has been achieved using chiral mono- $N$-protected $a$-amino- $O$-methylhydroxamic acid (MPAHA) ligands. Both chiral benzylamines and ortho-arylated benzylamines are obtained in high enantiomeric purity. The use of a readily removable nosyl (Ns) protected amino group as the directing group is a crucial practical advantage. Moreover, the ortho-arylated benzylamine products could be further transformed into chiral 6-substituted 5,6-dihydrophenanthridines as important structural motifs in natural products and bioactive molecules.
\end{abstract}

\section{TOC Graphic}

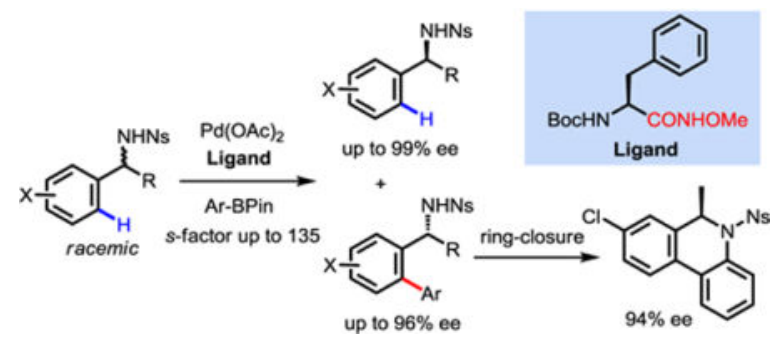

\section{Introduction}

Enantiopure $a$-branched amines are highly important structural motifs found prevalent in many natural products and biologically active compounds. In particular, chiral ortho-arylated benzylamines are known to be medicinally important motifs with a wide range of biological activities including CYP450 3A inhibition, $\gamma$-secretase modulation, and FVIIa inhibition (Figure 1). ${ }^{1}$ Consequently, a plethora of methods for the asymmetric synthesis of chiral amines have been developed. ${ }^{2}$ Among them, asymmetric addition of carbanions to aldimines/sulfinimines, ${ }^{3}$ asymmetric reduction/hydrogenation of ketimines/enamines/ enamides, ${ }^{4}$ and asymmetric hydroamination of alkenes are most extensively investigated. ${ }^{5}$ Despite these impressive advances, the enzymatic kinetic resolution and classical resolution via diastereomeric salt formation are still frequently used in manufacturing. ${ }^{6}$ Notably, non-

*yu200@scripps.edu.

Supporting Information Available. Detailed experimental procedures, characterization of new compounds. This material is available free of charge via the Internet at http://pubs.acs.org. 
enzymatic kinetic resolution of amines by acylation catalysts remains a significant challenge (Scheme 1a). ${ }^{7}$

Considering the limited success of kinetic resolution of amines via acylation, we envisioned that kinetic resolution of racemic benzylamines via a palladium(II)-catalyzed enantioselective $\mathrm{C}-\mathrm{H}$ cross-coupling ${ }^{8}$ would be appealing, as this approach will give access to both chiral benzylamines and ortho-arylated benzylamines. Despite significant progress in the development of enantioselective $\mathrm{C}-\mathrm{H}$ functionalization reactions via desymmetrization, ${ }^{9-12}$ enantioselective $\mathrm{C}-\mathrm{H}$ activation reactions through a kinetic resolution process are rare. ${ }^{13}$ Recently enantioselective $\mathrm{C}-\mathrm{H}$ iodination ${ }^{14}$ and enantioselective $\mathrm{C}-\mathrm{H}$ olefination ${ }^{15}$ via kinetic resolution were achieved utilizing $\mathrm{Pd}$ (II) coordinated with mono- $N$ protected amino acid (MPAA) ligand as the catalyst. ${ }^{9,14,15}$ To the best of our knowledge, kinetic resolution via palladium-catalyzed enantioselective $\mathrm{C}-\mathrm{H}$ cross-coupling has not been demonstrated to date. The elementary steps of $\mathrm{C}-\mathrm{H}$ cross-coupling are fundamentally different from that of the $\mathrm{C}-\mathrm{H}$ iodination ${ }^{14}$ and enantioselective $\mathrm{C}-\mathrm{H}$ olefination, ${ }^{15}$ which suggests that the development of a different chiral ligand may be necessary. From the viewpoint of synthetic utility, enantioselective $\mathrm{C}-\mathrm{H}$ cross-coupling affords highly valuable chiral bis-aryl compounds. Herein, we report a Pd(II)-catalyzed highly enantioselective C-H cross-coupling/kinetic resolution of racemic benzylamines with arylboronic acid pinacol esters using a chiral mono- $N$-protected $a$-amino- $O$-methylhydroxamic acid (MPAHA) ligand (Scheme 1b). Notably, the amino moiety protected by the commonly used nosyl (Ns) group is used as the directing group, representing a practical advantage in synthetic applications. In contrast to traditional acylative kinetic resolution, this asymmetric reaction not only separates two enantiomers of racemic benzylamines, but also installs a new carboncarbon bond, ${ }^{16}$ thereby providing a valuable method for the preparation of chiral orthoarylated benzylamines.

\section{Results and Discussion}

We initiated our studies by exploring the enantioselective $\mathrm{C}-\mathrm{H}$ cross-coupling/kinetic resolution of racemic nosyl (Ns) protected 1-(2-methylphenyl)ethanamine 1a. Guided by our previous conditions for $\mathrm{C}-\mathrm{H}$ cross-coupling of triflyl-protected amines, ${ }^{17}$ the reaction of $\mathbf{1 a}$ with para-methoxycarbonylphenylboronic acid pinacol ester was carried out in the presence of $10 \mathrm{~mol} \% \mathrm{Pd}(\mathrm{OAc})_{2}, 30 \mathrm{~mol} \%$ Boc-L-Ala-OH, 3.0 equiv of $\mathrm{Na}_{2} \mathrm{CO}_{3}, 2.0$ equiv of $\mathrm{Ag}_{2} \mathrm{CO}_{3}, 0.4$ equiv of DMSO and 5.0 equiv of $\mathrm{H}_{2} \mathrm{O}$ in $t$-AmylOH at $50{ }^{\circ} \mathrm{C}$. We were pleased to find that the desired cross-coupled product 2aa and the recovered starting material 1a were obtained with 58\% ee and $93 \%$ ee respectively, corresponding to a selectivity factor $(s)^{18}$ of 12 (Table 1, entry 1). Encouraged by this result, a variety of commercially available Boc protected amino acid ligands with different side chains were screened (entries 2-5). Boc-L-Phe-OH (L1) gave the best $s$-factor of 19 (entry 5). However, further tuning the $N$ protecting group only led to the decreased selectivities (entries 6 and 7). Influenced by our previous observation that conversion of the carboxylic acid in MPAA ligand to hydroxamic acid can be beneficial to enantioselective C-H activation reactions, ${ }^{9}$ a series of mono- $N$ protected $a$-amino- $o$-methylhydroxamic acid (MPAHA) ligands were investigated. This effort led to a significant improvement with Boc-L-Leu-NHOMe (L8) giving an excellent $s$ factor of 73 (entry 8). Replacing Boc with Cbz and Fmoc only gave inferior results (entries 9 
and 10, $s=47$ and 29, respectively). Further tuning the side chains revealed that Boc-L-PheNHOMe (L14) gave the best $s$-factor of 77 (entries 11-14). Notably, increasing the ligand loading to $20 \mathrm{~mol} \%$ gave a similar $s$-factor albeit a decreased conversion (entry 15). Most likely, excessive ligand can lead to the formation of $\mathrm{Pd}(\mathrm{II})$ complexes coordinated to two MPAHA ligands which will prevent substrate binding. When the temperature was raised to $55^{\circ} \mathrm{C}$, the $s$-factor was slightly decreased to 68 (entry 16). The absolute configuration of 2aa was determined to be $R$ by X-ray crystallographic analysis (Figure 2), thus providing important information for the establishment of a stereo-model in the kinetic resolution process through $\mathrm{C}-\mathrm{H}$ activation.

With the optimized reaction conditions in hand, we next investigated the scope of the arylboronic acid coupling partner. To our delight, the enantioselective $\mathrm{C}-\mathrm{H}$ cross-coupling of racemic benzylamine 1a with a variety of arylboronic acid pinacol esters proceeded smoothly to provide the desired products with excellent $s$-factor values (Table 2). The reaction with para-methoxycarbonylphenylboronic acid pinacol ester provided $47 \%$ yield of the arylated product $2 \mathbf{a a}$ in $91 \%$ ee, accompanied with $46 \%$ yield of recovered 1a in $96 \%$ ee $(s=77)$. Fluoro- and trifluromethyl-substituted phenylboronic acid pinacol esters were also suitable coupling partners, affording the corresponding products with $s$-factor values ranging from 96 to 107 (2ab-2ad). Functional groups such as aryl chlorides (2ae, $s=100$ ), nitriles (2af, $s=67$ ), and ketones (2ag, $s=73$ ) were well tolerated. Coupling partners containing electron-donating methyl and methoxy groups also performed well and gave the crosscoupled products in excellent selectivity factors (2ah and 2ai, $s=103$ and 98, respectively). In general, the structures of the organoboronic acids do not have significant impact on the $s$ factor, which is consistent with the enantioselectivity being determined by the $\mathrm{C}-\mathrm{H}$ activation step.

We then examined the amine scope of the kinetic resolution process. We were pleased to find that our protocol was tolerant of a variety of substituents on the phenyl ring, giving the corresponding products in high enantioselectivities (Table 3). Both electron-withdrawing (2b-2f) and electron-donating (2g) benzylamines were reactive. The chloride-containing substrates were also suitable for this enantioselective cross-coupling ( $\mathbf{2 c}, \mathbf{2 f}$ and $\mathbf{2 h}$ ), although the 2,4-dichlorinated substrate gave a slightly decreased conversion of $43 \%$ (2h, $s$ =75). While the reaction with ortho- and meta-substituted substrates provided only the mono-arylated products, the reaction of para-substituted and unsubstituted substrates gave a mixture of mono- and di-arylated products ( $2 \mathbf{i}$ and $\mathbf{2} \mathbf{j}, s=87$ and 72 , respectively). A series of different alkyl-substituted amines were also subjected to the reaction conditions. Primary alkyl-substituted substrates afforded excellent $s$-factor values (2k and $\mathbf{2 l}, s=72$ and 122, respectively). The secondary cyclopropyl-substituted amine $\mathbf{1 m}$ proceeded smoothly with an $s$-factor of 100, but bulkier isopropyl-substituted substrate $\mathbf{1 n}$ led to a decrease in conversion $(\mathrm{C}=38 \%, s=93)$. The results obtained with substrates $\mathbf{1 k}-\mathbf{n}$ containing the same metachloro phenyl group suggests that the size of alkyl chain has moderate effect on enantioselectivity with the longest chain butyl group affording the highest $s$-factor. This trend is consistent with the stereomodel proposed for kinetic resolution via $\mathrm{C}-\mathrm{H}$ olefination enabled by an analogous chiral MPAA ligands. ${ }^{15}$ The reaction with racemic $a$-amino acid 10 also produced the arylated product in high enantioselectivity, albeit with a reduced $s$ - 
factor of 34. Importantly, this enantioselective $\mathrm{C}-\mathrm{H}$ activation method can also be applied to prepare chiral $\beta$-amino alcohols ( $2 \mathbf{p}, s=95)$, an important class of molecules with broad applications as chiral synthons and chiral auxiliaries in asymmetric synthesis. ${ }^{19}$ Comparison between substrates $1 \mathbf{1 o}$ and $\mathbf{1 p}$ containing the same ortho-chloro phenyl group indicates that sterically hindered alkyl chain gives better enantioselectivity.

To demonstrate the synthetic utility of this enantioselective $\mathrm{C}-\mathrm{H}$ activation reaction, a gramscale experiment was carried out using racemic 1 f under the optimal reaction conditions. The cross-coupled product $2 \mathbf{f}$ was obtained in $45 \%$ yield with $94 \%$ ee, and the recovered starting material 1f was isolated in $42 \%$ yield with $91 \%$ ee (Scheme 2a). Importantly, the nosyl protecting group was readily removed under mild conditions (Scheme 2b). Moreover, the arylated product $\mathbf{2 f}$ was further transformed into 6-substituted 5,6-dihydrophenanthridine 4 without loss of optical activity by an NIS-mediated ring-closure (Scheme 2c). It should be noted that 6-substituted 5,6-dihydrophenanthridines are important structural units in natural products and biologically active molecules. ${ }^{20}$

\section{Conclusion}

In conclusion, we have developed an unprecedented kinetic resolution process for nosylprotected benzylamines via $\mathrm{Pd}$ (II)-catalyzed enantioselective $\mathrm{C}-\mathrm{H}$ cross-coupling. This approach allows for rapid preparation of both chiral benzylamines and ortho-arylated benzylamines in high enantioselectivities. The use of Ns-protected amines as substrates is an important practical advantage for synthetic applications. In addition, NIS-mediated ringclosure of enantioenriched ortho-arylated benzylamines provides a convenient access to the highly valuable chiral 6-substituted 5,6-dihydrophenanthridines. Currently, the incompatibility of this reaction with heterocyclic substrates is a limitation that remains to be overcome.

\section{Experimental Section}

\section{General Procedure for Kinetic Resolution of Benzylamines via Palladium(II)-Catalyzed C-H Cross-coupling}

Substrate rac-1 ( $0.2 \mathrm{mmol}, 1.0$ equiv), $\mathrm{Pd}(\mathrm{OAc})_{2}$ ( 0.1 equiv), L14 ( 0.15 equiv), $\mathrm{Ar}-\mathrm{BPin}$ (1.0 equiv), $\mathrm{Ag}_{2} \mathrm{CO}_{3}$ (2.0 equiv), $\mathrm{Na}_{2} \mathrm{CO}_{3}$ (3.0 equiv), $\mathrm{BQ}$ ( 0.5 equiv), DMSO ( 0.4 equiv), $\mathrm{H}_{2} \mathrm{O}$ (5.0 equiv) and $t$ - $\mathrm{AmylOH}(1.0 \mathrm{~mL})$ were added into a $10 \mathrm{ml}$ sealed tube. The reaction vessel was evacuated and backfilled with nitrogen $(\times 3)$. The reaction mixture was heated to $50{ }^{\circ} \mathrm{C}$ for $15 \mathrm{~h}$ under vigorous stirring. After being cooled to room temperature, the reaction mixture was diluted with EtOAc and filtered through a pad of Celite, eluting with EtOAc. The filtrate was concentrated under vacuum and the resulting residue was purified by preparative TLC using EtOAc/hexanes as the eluent to produce the desired product. The ee value was determined on a Hitachi LaChrom HPLC system using commercially available chiral columns as described below.

\section{Supplementary Material}

Refer to Web version on PubMed Central for supplementary material. 


\section{Acknowledgments}

We gratefully acknowledge The Scripps Research Institute and the NIH (NIGMS, 2R01GM084019) for financial support.

\section{References}

1. (a) Coburn CA, Maletic M, Luo Y, Qi Z, Li C, Yu T, Soll R. WO2014194519 A1. 2014(b) Xin Z, Peng H, Zhang A, Talreja T, Kumaravel G, Xu L, Rohde E, Jung M, Shackett MN, Kocisko D, Chollate S, Dunah AW, Snodgrass-Belt PA, Arnold HM, Taveras AG, Rhodes KJ, Scannevin RH. Bioorg Med Chem Lett. 2011; 21:7277. [PubMed: 22061640] (c) Priestley ES, De Lucca I, Zhou J, Zhou J, Saiah E, Stanton R, Robinson L, Luettgen JM, Wei A, Wen X, Knabb RM, Wong PC, Wexler RR. Bioorg Med Chem Lett. 2013; 23:2432. [PubMed: 23478148]

2. Nugent, TC., editor. Chiral Amine Synthesis: Methods, Developments and Applications. WileyVCH; Weinheim: 2010.

3. For a review on asymmetric synthesis of chiral amines via imine addition, see:(a) Kobayashi S, Mori Y, Fossey JS, Salter MM. Chem Rev. 2011; 111:2626. [PubMed: 21405021] For a review on asymmetric synthesis of chiral amines via sulfinimine chemistry, see:(b) Robak MT, Herbage MA, Ellman JA. Chem Rev. 2010; 110:3600. [PubMed: 20420386]

4. For recent reviews on asymmetric synthesis of chiral amines via asymmetric reduction/ hydrogenation of ketimines/enamines/enamides, see:(a) Xie JH, Zhu SF, Zhou QL. Chem Rev. 2011; 111:1713. [PubMed: 21166392] (b) Nugent TC, El-Shazly M. Adv Synth Catal. 2010; $352: 753$.

5. For selected examples on asymmetric synthesis of chiral amines via asymmetric hydroamination of alkenes, see:(a) Miki Y, Hirano K, Satoh T, Miura M. Angew Chem Int Ed. 2013; 52:10830.(b) Zhu S, Niljianskul N, Buchwald SL. J Am Chem Soc. 2013; 135:15746. [PubMed: 24106781]

6. For a review on industrial methods for the asymmetric synthesis of chiral amines, see:(a) Breuer M, Ditrich K, Habicher T, Hauer B, Kesseler M, Stürmer R, Zelinski T. Angew Chem Int Ed. 2004; 43:788. For an example of chemoenzymatic dynamic kinetic resolution of amines, see:(b) Paetzold J, Bäckvall JE. J Am Chem Soc. 2005; 127:17620. [PubMed: 16351088]

7. For a review on nonenzymatic acylative kinetic resolution of racemic amines and related compounds, see:(a) Krasnov VP, Gruzdev DA, Levit GL. Eur J Org Chem. 2012:1471.For selected examples, see:(b) Arai S, Bellemin-Lapponaz S, Fu GC. Angew Chem Int Ed. 2001; 40:234.(c) Arseniyadis S, Valleix A, Wagner A, Mioskowski C. Angew Chem Int Ed. 2004; 43:3314.(d) De CK, Klauber EG, Seidel D. J Am Chem Soc. 2009; 131:17060. [PubMed: 19929016] For an example of asymmetric synthesis of $\beta$-amino acid derivatives via kinetic resolution of $\beta$-lactams, see:(e) Bumbu VD, Birman VB. J Am Chem Soc. 2011; 133:13902. [PubMed: 21823609]

8. For examples of $\mathrm{C}-\mathrm{H}$ ortho-arylation of benzylamines, see:(a) Lazareva A, Daugulis O. Org Lett. 2006; 8:5211. [PubMed: 17078680] (b) Feng R, Yao J, Liang Z, Liu Z, Zhang Y. J Org Chem. 2013; 78:3688. [PubMed: 23510158] (c) Zhang JC, Shi JL, Wang BQ, Hu P, Zhao KQ, Shi ZJ. Chem Asian J. 2015; 10:840. [PubMed: 25605476]

9. For examples of enantioselective Pd(II)-catalyzed C-H activation from our laboratory, see:(a) Shi BF, Maugel N, Zhang YH, Yu JQ. Angew Chem Int Ed. 2008; 47:4882.(b) Shi BF, Zhang YH, Lam JK, Wang DH, Yu JQ. J Am Chem Soc. 2010; 132:460. [PubMed: 20017549] (c) Wasa M, Engle KM, Lin DW, Yoo EJ, Yu JQ. J Am Chem Soc. 2011; 133:19598. [PubMed: 22059375] (d) Chu L, Wang XC, Moore CE, Rheingold AL, Yu JQ. J Am Chem Soc. 2013; 135:16344. [PubMed: 24151991] (e) Xiao KJ, Lin DW, Miura M, Zhu RY, Gong W, Wasa M, Yu JQ. J Am Chem Soc. 2014; 136:8138. [PubMed: 24815880] (f) Chan KSL, Fu H, Yu JQ. J Am Chem Soc. 2015; 137:2042. [PubMed: 25581489] (g) Laforteza BN, Chan KSL, Yu JQ. Angew Chem Int Ed. 2015; 54:11143.

10. For examples of enantioselective Pd(II)-catalyzed C-H activation from others, see:(a) Gao DW, Shi YC, Gu Q, Zhao ZL, You SL. J Am Chem Soc. 2013; 135:86. [PubMed: 23253097] (b) Pi C, Li Y, Cui X, Zhang H, Han Y, Wu Y. Chem Sci. 2013; 4:2675.(c) Du ZJ, Guan J, Wu GJ, Xu P, Gao LX, Han FS. J Am Chem Soc. 2015; 137:632. [PubMed: 25569141] For an example of Pd-catalyzed 
atropselective arylation, see:(d) Yamaguchi K, Yamaguchi J, Studer A, Itami K. Chem Sci. 2012; 3:2165.

11. For examples of enantioselective $\mathrm{Pd}(0)$-catalyzed $\mathrm{C}-\mathrm{H}$ activation, see:(a) Albicker MR, Cramer N. Angew Chem Int Ed. 2009; 48:9139.(b) Renaudat A, Jean-Gérard L, Jazzar R, Kefalidis CE, Clot E, Baudoin O. Angew Chem Int Ed. 2010; 49:7261.(c) Anas S, Cordi A, Kagan HB. Chem Comm. 2011; 47:11483. [PubMed: 21927738] (d) Nakanishi M, Katayev D, Besnard C, Kündig EP. Angew Chem Int Ed. 2011; 50:7438.(e) Saget T, Lemouzy SJ, Cramer N. Angew Chem Int Ed. 2012; 51:2238.(f) Nakanishi M, Katayev D, Besnard C, Kündig EP. Chimia. 2012; 66:241. [PubMed: 22613159] (g) Martin N, Pierre C, Davi M, Jazzar R, Baudoin O. Chem Eur J. 2012; 18:4480. [PubMed: 22407525]

12. For an example of Ru-catalyzed atropselective alkylation in moderate ees, see:(a) Kakiuchi F, Le Gendre P, Yamada A, Ohtaki H, Murai S. Tetrahedron: Asymmetry. 2000; 11:2647.For examples of enantioselective Ir(I)-catalyzed C-H activation, see:(b) Pan S, Endo K, Shibata T. Org Lett. 2011; 13:4692. [PubMed: 21812393] (c) Shibata T, Shizuno T. Angew Chem Int Ed. 2014; 53:5410.For an example of enantioselective Rh-catalyzed silylation, see:(d) Lee T, Wilson TW, Berg R, Ryberg P, Hartwig JF. J Am Chem Soc. 2015; 137:6742. [PubMed: 25948056] For examples of $\mathrm{C}-\mathrm{H}$ activation followed by enantioselective addition to olefins, see:(e) Mikami K, Hatano M, Terada M. Chem Lett. 1999:55.(f) Thalji RK, Ellman JA, Bergman RG. J Am Chem Soc. 2004; 126:7192. [PubMed: 15186153] (g) Hyster TK, Knörr L, Ward TR, Rovis T. Science. 2012; 338:500. [PubMed: 23112327] (h) Ye B, Cramer N. Science. 2012; 338:504. [PubMed: 23112328]

13. Larrow JF, Jacobsen EN. J Am Chem Soc. 1994; 116:12129.

14. (a) Chu L, Xiao KJ, Yu JQ. Science. 2014; 346:451. [PubMed: 25342799] For a Pd-catalyzed atropselective $\mathrm{C}-\mathrm{H}$ iodination via kinetic resolution in modest selectivity, see:(b) Gao DW, Gu Q, You SL. ACS Catal. 2014; 4:2741.

15. Xiao KJ, Chu L, Yu JQ. Angew Chem Int Ed. 2016; 55:2856.

16. For selected examples on kinetic resolution with carbon-carbon bond formation, see:(a) Tanaka K, Fu GC. J Am Chem Soc. 2003; 125:8078. [PubMed: 12837058] (b) Bandini M, Cozzi PG, Melchiorre P, Umani-Ronchi A. Angew Chem Int Ed. 2004; 43:84.(c) Lei BL, Ding CH, Yang XF, Wan XL, Hou XL. J Am Chem Soc. 2009; 131:18250. [PubMed: 19994886] (d) Mao B, Ji Y, fañanàs-Mastral M, Caroli G, Meetsma A, Feringa BL. Angew Chem Int Ed. 2012; 51:3168.

17. Chan KSL, Wasa M, Chu L, Laforteza BN, Miura M, Yu JQ. Nat Chem. 2014; 6:146. [PubMed: 24451591]

18. The selectivity factor $(\mathrm{s})=$ (rate of fast-reacting enantiomer $) /($ rate of slow-reacting enantiomer $)=$ $\ln [(1-\mathrm{C})(1-\mathrm{ee})] / \ln [(1-\mathrm{C})(1+\mathrm{ee})]$ where $\mathrm{C}$ is the conversion and ee is the enantiomeric excess of the remaining starting material.Kagan HG, Fiaud JC. Top Stereochem. 1988; 18:249.

19. Ager DJ, Prakash I, Schaad DR. Chem Rev. 1996; 96:835. [PubMed: 11848773]

20. (a) John MA, Anthony AM, Hugh RB, Arturo FA, Jay MW. WO2004050631 A1. 2004(b) Fotie J, Bohle DS, Olivier M, Gomez MA, Nzimiro S. J Nat Prod. 2007; 70:1650. [PubMed: 17880175] (c) Éles J, Beke G, Vágó I, Bozó É, Huszár J, Tarcsay Á, Kolok S, Schmidt É, Vastag M, Hornok K, Farkas S, Domány G, Keseru GM. Bioorg Med Chem Lett. 2012; 22:3095. [PubMed: 22483585] 


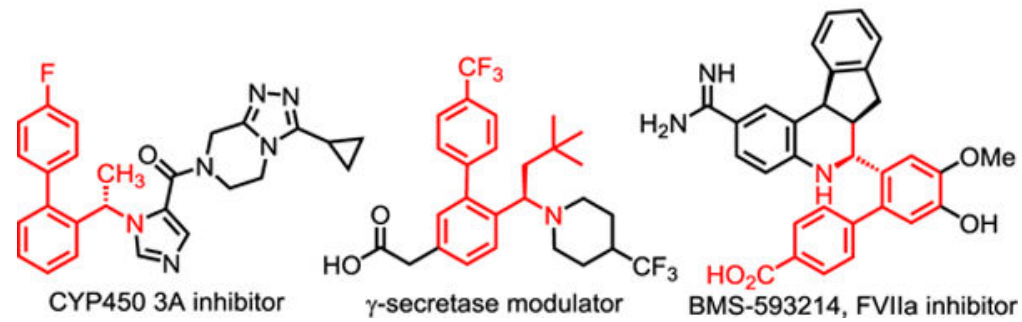

Figure 1.

Bioactive compounds containing ortho-arylated benzylamines. 


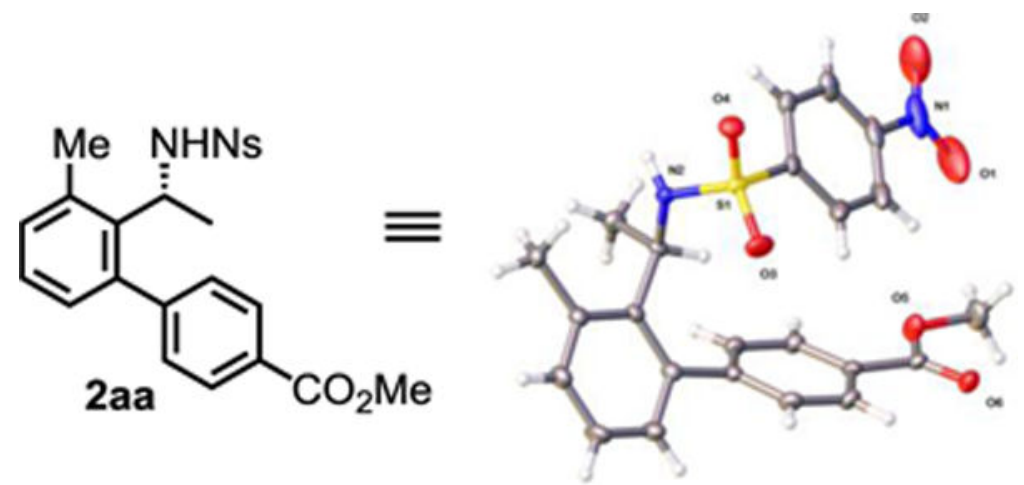

Figure 2.

X-ray crystal structure of $2 \mathrm{aa}$. 
(a) Traditional acylative kinetic resolution

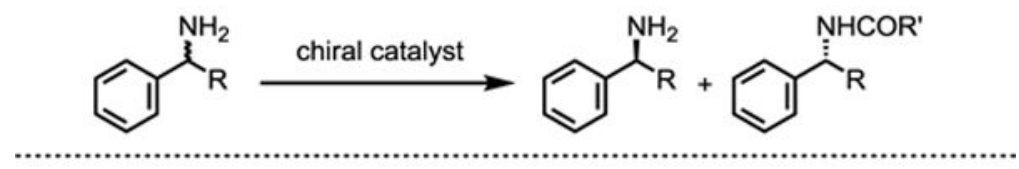

(b) Kinetic resolution via enantioselective $\mathrm{C}-\mathrm{H}$ functinalization (this work)

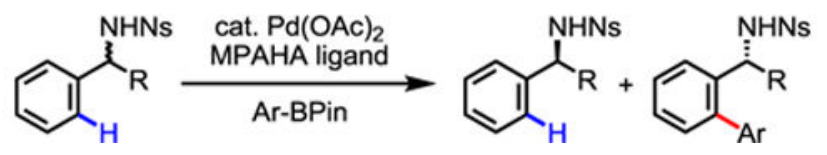

Scheme 1.

Kinetic Resolution of Racemic Benzylamines. 
(a)

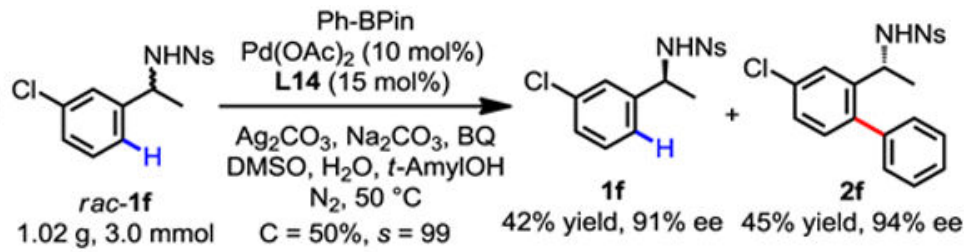
$1.02 \mathrm{~g}, 3.0 \mathrm{mmol}$ $\mathrm{C}=50 \%, s=99$

$42 \%$ yield, $91 \%$ ee $45 \%$ yield, $94 \%$ ee

(b)
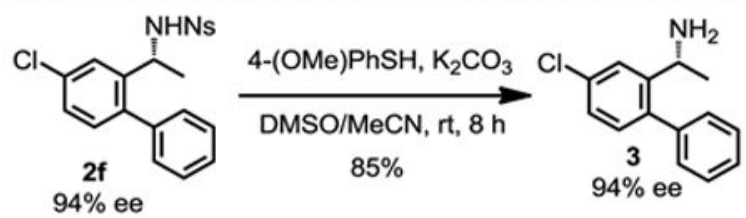

(c)
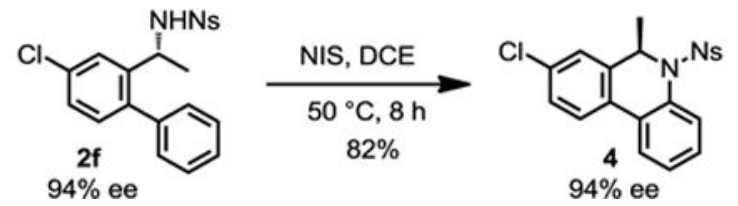

Scheme 2.

Synthetic Applications. 

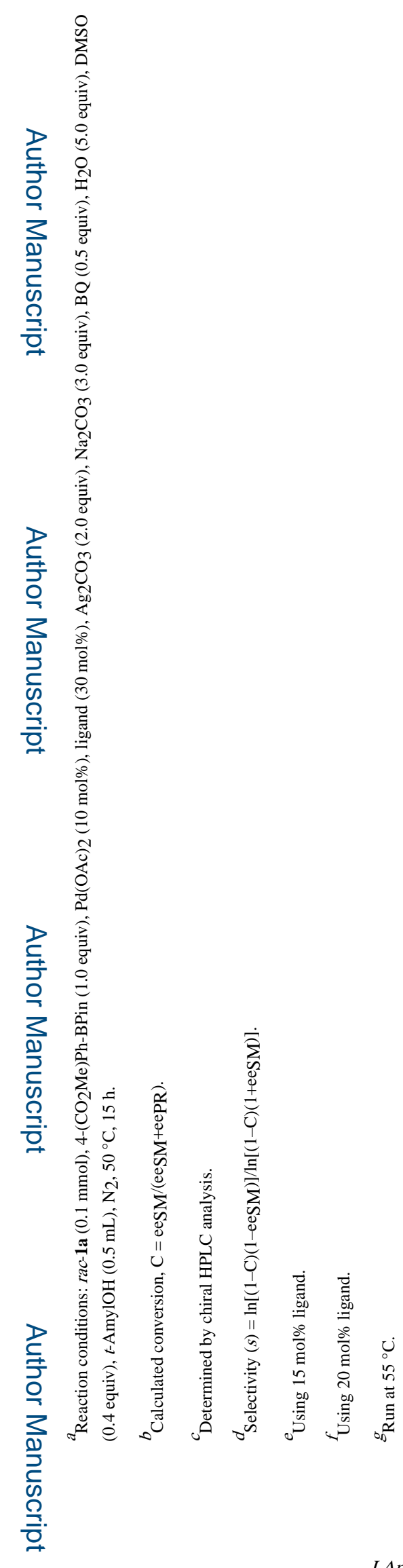

J Am Chem Soc. Author manuscript; available in PMC 2017 July 19. 


\section{Table 2}

Scope of Arylboronic Acid Coupling Partners ${ }^{a, b}$

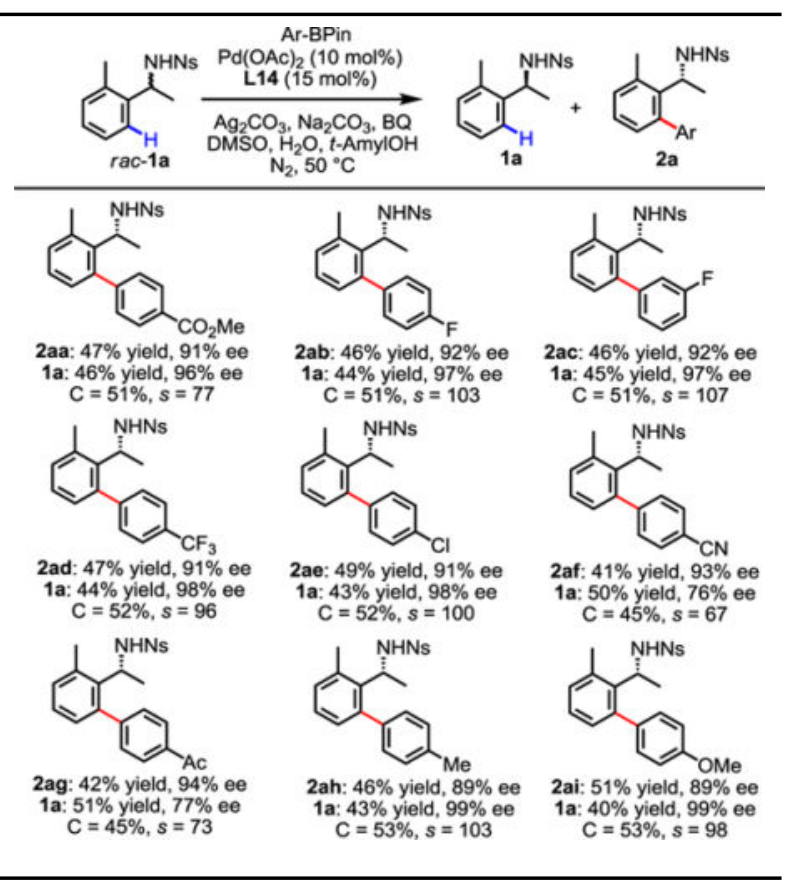

${ }^{a}$ Reaction conditions: rac-1a (0.2 mmol), Ar-BPin (1.0 equiv), $\mathrm{Pd}(\mathrm{OAc}) 2$ (10 mol $\left.\%\right), \mathbf{L 1 4}(15 \mathrm{~mol} \%), \mathrm{Ag}_{2} \mathrm{CO}_{3}$ (2.0 equiv), $\mathrm{Na}_{2} \mathrm{CO}_{3}$ (3.0 equiv), $\mathrm{BQ}\left(0.5\right.$ equiv), $\mathrm{H}_{2} \mathrm{O}$ (5.0 equiv), DMSO (0.4 equiv), $t-\mathrm{AmylOH}(0.5 \mathrm{~mL}), \mathrm{N}_{2}, 50^{\circ} \mathrm{C}, 15 \mathrm{~h}$.

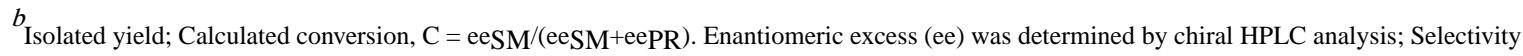
$(s)=\ln [(1-\mathrm{C})(1-\mathrm{eeSM})] / \ln [(1-\mathrm{C})(1+\mathrm{eeSM})]$. 


\section{Table 3}

Scope of Benzylamine Substrates ${ }^{a, b}$

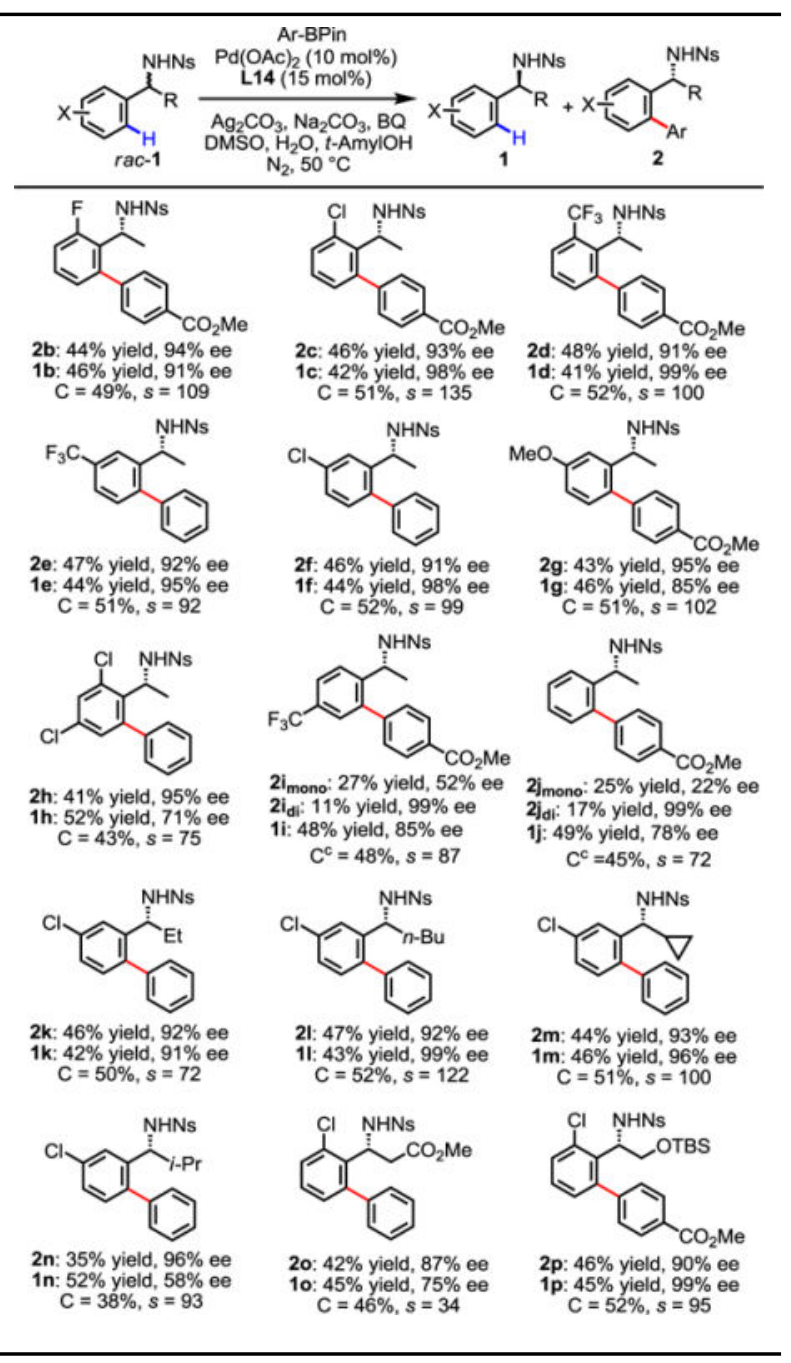

${ }^{a}$ Reaction conditions: rac-1 (0.2 mmol), Ar-BPin (1.0 equiv), $\mathrm{Pd}(\mathrm{OAc}) 2$ (10 mol\%), L14 (15 mol\%), $\mathrm{Ag}_{2} \mathrm{CO}_{3}$ (2.0 equiv), $\mathrm{Na}_{2} \mathrm{CO}_{3}$ (3.0 equiv), BQ ( 0.5 equiv), $\mathrm{H}_{2} \mathrm{O}$ (5.0 equiv), DMSO ( 0.4 equiv), $t-\mathrm{AmylOH}(0.5 \mathrm{~mL}), \mathrm{N}_{2}, 50^{\circ} \mathrm{C}, 15 \mathrm{~h}$.

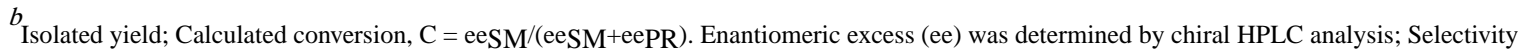
$(s)=\ln [(1-\mathrm{C})(1-$ eesM $)] / \ln [(1-\mathrm{C})(1+$ eesM $)]$.

${ }^{c}$ Conversion was determined by crude H-NMR. 